\title{
Corporeïtat, conflicte i abjecció en Les mans de la deixebla d'Anna Moner
}

\section{Corporeality, conflict and abjection in Anna Moner's novel Les mans de la deixebla}

\author{
Irene Mira-Navarro \\ irene.mira@ua.es \\ Universitat d'Alacant
}

\begin{abstract}
Resum: Aquest article té per objectiu analitzar la novel la Les mans de la deixebla d'Anna Moner (2011) com una obra a cavall entre la narració gòtica i l'ambientació històrica en el segle xviii, d'una banda, i com a exponent de la representació de la corporeitat, d'una altra. Estudiem els mecanismes a través dels quals l'autora construeix tres personatges complexos que giren al voltant del conflicte generat per la naturalesa abjecta (Kristeva 2006) del cos de la protagonista. A partir d'aquest punt, ens proposem explorar com les mans deformades esdevenen un símbol que connecten amb la tradició gòtica (Cornich i Sedgwick 2017) i que en aquesta novel la funcionen com un agent que distorsiona la psicologia de la protagonista. Estudiarem el procés d'abjecció del personatge principal en relació al rebuig del propi cos i alhora a la instrumentalització d'aquest com a agent capaç de fer trontollar la concepció il lustrada de la ciència com a mitjà de progrés.
\end{abstract}

Paraules clau: corporeïtat, abjecció, psicologisme, novel la gòtica, dissecció.

Abstract: The main aim of this article is to analyse the novel Les mans de la deixebla by Anna Moner (2011) both as a novel through gothic narration and the historical environment of the XVIII century, and as the exponent of the corporeality's representation. We study the mechanisms through which the author builds three complex characters that turn around the conflict generated by the abject nature of the main character's body (Kristeva 2006). From this point on, we look to explore how the deformed hands become into a symbol that connects with the gothic tradition (Cornich and Sedgwick 2017). In this novel, the hands also play the role of a disruptive agent of the main character's psychology. We will study the abjection process of the main character related to the rejection of the own body and, at the same time, to its instrumentalization as an agent capable of undermining the illustrated conception of science as a means of progress.

Keywords: corporeality, abjection, psycologism, Gothic novel, dissection. 


\section{Introducció}

La poeta Montserrat Abelló expressava a través dels versos que la pròpia corporeïtat és, en ocasions, un exercici d'alteritat en què el cos no sempre és una part constitutiva de l'ésser sinó un canal complementari per a acostar-se al món i a la literatura (Marcer 2013). Per a aquesta autora, el cos, i en concret les mans, són una extensió semi independent que fa de mitjancera entre el jo i l'entorn, com veiem en aquest poema:

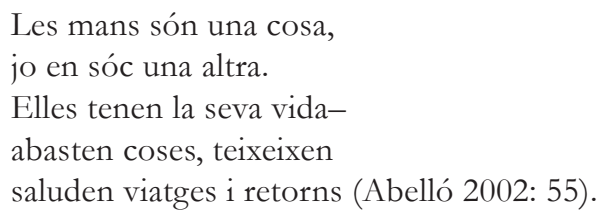

La doble qualificació de les mans com a parts de la identitat del jo literari d'una banda, i com a elements externs i alteritzats d'altra banda, ens ha portat a qüestionar-nos la representació problemàtica d'aquesta extremitat en la novel la Les mans de la deixebla d'Anna Moner (2011). L'interés per la fixació de la imatge literària de la mà efectuada per Moner (Vila-real, 1967) ens ha obert les portes a explorar els mecanismes narratius que aquesta obra empra per a constituir-se com una novel la a cavall de la narració psicològica, el gènere gòtic i l'interés per la història de la ciència gràcies a la representació de la corporeïtat.

La crítica coincideix a afirmar que l'estil narratiu conreat per Anna Moner al llarg de les tres novel les publicades -Les mans de la deixebla (2010), El retorn de l'hongarès (2015) i La mirada de vidre (2019) - és un territori personal adobat per una profusa documentació i reflexió sobre el context social, cultural i científic de les èpoques en què s’ambienten (Aliaga 2015, 2019 i Villalonga 2015). La naturalesa d'aquestes obres fa que s'allunyen del paradigma de la novel la històrica tradicional perquè, encara que es tracte de narracions ambientades en èpoques passades, el món pretèrit no és reflectit a través de l'al lusió a esdeveniments històrics i personatges reals sinó que és gràcies al plantejament filosòfic que el públic lector s'amera del període al ludit. En el cas de Les mans de la deixebla ens trobem, doncs, davant d'una obra d'ambientació històrica fixada al segle de les llums i ubicada a una alqueria de l'horta valenciana.

A partir d'aquest enquadrament, Moner dibuixa un personatge central que desplega el nus narratiu gràcies a un ús acurat del psicologisme: Brunel la, una jove protagonista aprenent de cirurgiana. Complementàriament, dos personatges masculins juguen un paper fonamental en la constitució de la protagonista. D'una banda, el cirurgià Fabrizzio Scarpa, mentor de l'aprenent que sobreviu en els records i en el llibre de memòries que aquesta en conserva. I, d'una altra banda, Zacaries, l'ajudant que satisfà les demandes d'una Brunel la, ara convertida en la seua ama, després de la mort de Scarpa.

A grans trets, aquestes circumstàncies vinculen l'estètica de Moner a les característiques del gènere gòtic, i encara que no s'hi ajusta totalment perquè hi manca l'ambientació prototípica en fortaleses o 
monestirs, l'enigma a descobrir o la presència del personatge malvat, s'hi identifiquen components que ens permeten acostar-la a l'àrea d'influència d'aquest corrent. Es tracta, especialment, del tractament plàstic de les imatges referides al cos i al patiment, tant físic com moral, propi del gòtic, com indica Míriam López Santos (2008), i que tot seguit analitzarem.

\section{Entre el llegat i el mestratge}

Com si d'una cadena es tractara, Brunel la és la baula central que depén del mestratge i l'admiració més íntima i sensual cap a Scarpa, i alhora és l'ancoratge al qual se supedita Zacaries en una relació quasi fetitxista i submisa. Així doncs, els tres personatges principals de la narració estan connectats per un fil afectiu que els vincula en relacions jeràrquiques pel que respecta a les posicions de poder. La doble condició, de mestra i aprenent, dicotomitza la figura de Brunel la, que assumeix dos papers contradictoris i, al mateix temps, complementaris. En ambdós casos, el vincle entre la protagonista $\mathrm{i}$ els dos personatges masculins està marcat per un fort component afectiu, gràcies a l'ús del cos femení com agent transmissor de significats i creador de les relacions dels personatges amb la protagonista. La pedra de toc, però, de la xarxa afectiva que els vincula és la realitat deforme i abjecta de les mans de la protagonista, les quals resulten asimètriques per l'absència del dit polze en l'extremitat esquerra i la duplicació d'aquest en la mà dreta. Aquesta distribució provoca una relació conflictiva de Brunel la amb les seues mans, les quals són objecte de rebuig com s'observa en la següent descripció:

Sobre la pedra, augmentada per la llangorosa il luminació del fanal, es reflectia una ombra deforme i bipartida que s'esvaí en el no-res quan amagà la mà entre la roba. Aquelles urpes funestes li generaven una angúnia visceral que s'engrandia amb el temps (Moner 2011: 31).

Aquesta visió de les mans manifesta un trencament del subjecte amb el seu cos perquè, si seguim les reflexions de Cornich i Sedgwick a propòsit de la representació literària de les mans en la novel la gòtica, veurem que en aquest cas traeixen la intimitat de la protagonista. Els crítics exposen les funcions de les mans en la següent idea: «Hands physically express the body's intelligence and creativity, enacting the mishes of the mind»(Cornich i Sedgwick 2017: 131). Aquesta reflexió també és present en Brunel la, la qual puntualitza que una part fonamental de la seua extensió material és una font d'incomoditat i de no reconeixement de la pròpia identitat:

Però, expliqueu-me, què fem de les mans? No és ben cert que amb elles expressem tot el que som? No és ben cert que les utilitzem per demanar, per rebutjar, per intimidar, per reganyar, per suplicar, per penedir-nos, per manar, per injuriar, per menysprear, per beneir, per dominar, per colpejar, per acariciar allò desitjat...? Contesteu-me, puix que jo no puc fer res d'això sense avergonyir-me'n, sense ocultar-les, humiliada, en apreciar l'horror o la compassió en l'esguard dels altres. (Moner 2011: 102) 
En conseqüència, s'observa que la deformació suposa per a la protagonista un distanciament del seu propi jo, l'alterització d'un conflicte corporal que posa en dubte la seua subjectivitat i la fa experimentar el que Julia Kristeva anomenava l’abjecció de si mateix:

\begin{abstract}
Si es cierto que lo abyecto solicita y pulveriza simultáneamente al sujeto, se comprenderá que su máxima manifestación se produce cuando, cansado de sus vanas tentativas de reconocerse fuera de sí, el sujecto encuentra lo imposible de sí mismo: cunado encuentra que lo imposible es su ser mismo, al descubrir que él no es otro que siendo abyecto (Kristeva 2006: 12).
\end{abstract}

Aquestes mans contrafetes són un punt de divergència entre la protagonista i el seu mestre, el cirurgià Scarpa, que les admira i les considera una benedicció:

\begin{abstract}
D'altra banda, no penses que la forma del teu dit és producte d'una aberració de la naturalesa. Allò que, amb seguretat, molts altres cirurgians qualificarien de fallada anatòmica, per a mi adquireix la categoria de prodigi, un prodigi atribuible al triomf excepcional de certes causes atzaroses que també formen part del pla diví, un prodigi materialitzat en un organisme harmoniós comparable amb una obra d'art (Moner 2011: 101).
\end{abstract}

La consideració quasi fetitxista del mentor pels dits bífids determina l'afectivitat entre ambdós personatges, ja que el cirurgià es negà a intervindre les mans que li despertaven un «sentiment d'estranya pertorbació», raó per la qual la protagonista esdevé deixebla amb l'objectiu de formar-se i autocorregir-se els mals del cos. Aquesta situació provoca que Brunel la se senta indefectiblement lligada a l'anatomista perquè creu que és l'únic amb possibilitats de restaurar el seu cos. Arran d'açò la protagonista inicia un procés de formació i obsessió per l'anatomia de les extremitats que es construeix paral lelament a una fonda obstinació per estar prop del mestre, font del coneixement quirúrgic. Així doncs, la relació s'assenta sobre les bases de la perversió que converteix Brunel la en un ésser fora de si que, a canvi d'adquirir les destreses mèdiques per a intervindre's, es mou entre l'atracció i la repulsió cap al cirurgià, com il lustra aquest fragment en què la protagonista és obsequiada amb una joia:

\footnotetext{
Els ulls [de Brunel la] encara retenien part de l'enuig en les pupil les i el mestre, en aprecebre's, tractà d'assossegar-la amb un regal, un ardit que practicava sovint per apaivagar els arravataments furiosos que la posseïen de tant en tant i conduir-la al seu terreny (...). Aleshores, després d'una pausa, varià el to alliçonador per un altre més lasciu. «Però, preciosa, açò és un troc. I tu, què em dones a canvi?» Tot seguit, relliscà la mà sota les faldilles (Moner 2011: 104).
}

A partir d'aquest moment, mestre i aprenent inicien un joc de seducció en què Brunel la ofereix sensualitat animal al mestre, mentre Scarpa exercita el control dels instints físics, com a mostra de la racionalitat il lustrada i la preeminència del coneixement de la naturalesa humana, perquè «de totes les victòries que un home pot arribar a assolir, la principal i la més gloriosa és el domini sobre ell mateix» (Moner 2011: 105). Com déiem, el cos de Brunel la en la novel la és oferit al mentor per 
a comprovar la fortalesa dels seus principis, un enfrontament entre natura i raó en què la darrera sempre en resulta victoriosa. No obstant això, el sensualisme de la protagonista es reforça en aquest joc de contraris desplegat en els records de la jove i en les al lucinacions que li produeix el làudan d'opi que consumeix compulsivament.

Complementàriament a la fixació per Scarpa i el seu coneixement, se'ns presenta una protagonista conscient de la solitud a què es veu abocada a l'alqueria de la València del segle XVIII on inverteix el temps en assajar amputacions al laboratori. La renúncia de les seues mans abjectes i fal lera per modificar-les enterboleix el caràcter de Brunel la que, convertida en la cap del lúgubre quiròfan, evoluciona cap a postulats que s'allunyen de la raó il lustrada com a motor de progrés social que en temps anteriors havia defensat el seu mestre; i es lliura a l'obsessió de recordar-lo i a practicar tècniques quirúrgiques que la conduïsquen al seu personal objectiu. Potser és en aquest moment que la novel la de Moner s'acosta amb més precisió a les característiques del gènere gòtic, ja que hi abunden els passatges dedicats a les disseccions en la tenebra de la nit, l'al lusió constant al dolor i l'escenificació de la sala d'intervencions a l'estil de Mary W. Shelley en recerca de la perfecció del cos. La materialitat corporal pren un paper predominant en les seccions en què la protagonista, ajudada per Zacaries, intervé mans de personatges marginals per a assajar i preparar el seu ajudant per al moment en què l'haja d'intervenir a ella. La novel la, per tant, s'acosta al món gòtic, ja que, com afirmen Cornich i Sedgwick, les operacions i les referències al món mèdic són una constant de les narracions gòtiques i, més en concret, les referides a les mans:

The dissection of the hand, as Katherine Rowe notes, persisted 'as one of the central moral topoi of anatomy demonstrations: celebrated for its difficulty and beauty, it reveals God's intentions as no other part can' (1997, p. 287) (Cornich i Sedgwick 2017: 132).

Així doncs, la narració de Moner descansa sobre un lloc comú propi dels tractats d'anatomia dels segles XVII i XVIII, en què la ciència i el control de la naturalesa havien de ser la palanca de canvi del món, ideals representats en la figura de Scarpa. Per contra, la pulsió d'abjecció que controla la subjectivitat de la protagonista s'allunya d'aquests plantejaments i provoca que les passions de Brunel la dominen els coneixements $\mathrm{i}$ els utilitzen per a modificar els designis divins. Les consecutives operacions perpetrades per la mestra i el seu aprenent donen a Brunel la el poder de Déu de controlar els cossos i modificar-los, fet que l'erigeix com a ama del destí d'unes vides desgraciades. En aquest sentit, les mans repudiades es converteixen en els millors instruments per a portar a terme les operacions, són subjecte per a posteriorment esdevenir objecte de l'abjecció. Les extremitats deformades són, per tant, transmissores dels desitjos de la ment, ara però, centrats en l'exploració i la dissecció d'aquestes mateixes. La instrumentalització dels polzes bífids converteix les mans en un símbol literari que fon en una sola entitat la corporeïtat $i$ la identitat de la protagonista en la carn malfeta. A través del cos deformat ella aprehén el món: 
The prehensile ability of the hand gives it immense significance and, as Kemp writes, «it is fitting that "apprehension" in Latin as in English came to assume the dual meaning of taking hold and becoming cognizant of new ideas» (2000, p. 22) (Cornich i Sedgwick 2017: 134).

En conseqüència, l'aprehensió del món per part de Brunel la està filtrada per la concepció de monstre atribuïda al propi cos. Des d'aquest punt de vista, la qualitat monstruosa de la protagonista en determina les accions i deshumanitza els subjectes amb els quals treballa al laboratori, com veurem més endavant.

Zacaries és un dels personatges que pateixen aquesta alterització per part de la protagonista. L'ajudant resulta, a ulls crítics, un ésser subjugat a les ordres de l'ama, ja que ella el prové econòmicament, alhora que alimenta els seus desitjos més íntims. Com hem esmentat anteriorment, les relacions que s'estableixen entre els personatges estan determinades per unes estructures de poder fortament influïdes per la corporeïtat. Si en el cas de Scarpa, Brunel la és la carn jove que el tempta i a la qual ell demostra que es pot resistir; en Zacaries l'anatomista canvia la seua posició i esdevé el cos que el manté en tensió gràcies al constant joc seductor.

L'intercanvi de papers s'observa en el tractament de «mestra» $i$ «ama» que Zacaries profereix a qui a ulls de Scarpa era una jove deixebla. En la narració la protagonista alimenta la submissió de l'ajudant en permetre-li observar-la durant els banys, fet que certifica la posició de control per a desenvolupar el seu pla:

\footnotetext{
[Zacaries] Ignorava que a Brunel la, l'obsessió l'havia obligada a desenvolupar des de l'adolescència una ment freda i calculadora i, ara, necessitava la complicitat d'aquell pobre xicot per aconseguir els seus propòsits. Per això, sempre permetia que l'espiàs mentre es banyava, precisava seduir-lo constantment, alimentar el desig des de la distància, generar en ell una passió ardent, capaç de conduir-lo a executar qualsevol cosa que ella li demanàs (Moner 2011: 42).
}

Els cos sexuat, per tant, es converteix en un dispositiu de control per part de la mestra que manipula la conducta del seu jove ajudant. Aquest ús de la corporalitat en tant que eina d'intervenció és una reacció a la negació d'operar-la que temps enrere Scarpa havia afectuat. El que abans havia estat una garantia per a accedir al coneixement, ara també s'instrumentalitza perquè Zacaries abastisca l'anatomista de cossos on experimentar la dissecció anhelada. En un sentit ampli, la protagonista posa el cos com a mitjà i com a objectiu. 


\section{Els cossos aliens}

La representació, però, de la corporeïtat no es redueix a les al lusions a Brunel la sinó que esdevé un mecanisme narratiu clau en l'estètica de Moner. En el cas de Les mans de la deixebla, l'autora utilitza la narració de les intervencions científiques de la incipient cirurgia del segle XVIII per a ambientar històricament el relat. Així doncs, les acurades descripcions detallen tot un seguit de procediments mèdics $i$ estris propis d'una època $i$ actuen com a fil conductor de la reflexió sobre la materialitat corporal que sura en l'obra.

En aquest sentit, pensem que la condició abjecta atribuïda al cos deformat va més enllà de la crisi identitària que pateix la protagonista, és una constant que repensa el tractament artístic del dolor, la mort i el cos. Aquest procediment es dona en la novel la amb la posada en escena de les amputacions i, en certa manera, en el desig de castració que algunes d'aquestes representen. Segons Cornich i Sedgwick (2017) les històries d'amputacions i disseccions, especialment de les extremitats, són un lloc recurrent del gènere gòtic; no obstant això, en Moner l'acostament a l'estètica respon a una necessitat narrativa: il lustrar el dolor propi a través d'un cos aliè.

Al llarg de la novel la les tres intervencions quirúrgiques perpetrades per la protagonista segueixen una línia ascendent pel que fa al grau de crueltat amb què són narrades. De la mateixa manera, l'obsessió de Brunel la per aconseguir l'èxit en les operacions augmenta amb el consum de làudan d'opi, cosa que provoca la degradació del personatge. En conseqüència, Moner deixa al descobert la naturalesa abjecta de la protagonista, que converteix els experiments en una revolta violenta contra allò que l'ha malmesa, vinga de fora o de dins (Kristeva 2006).

Per aquest motiu, la naturalesa abjecta ja no es redueix a les mans bífides de Brunel la sinó que impregna tot l'exercici de representació de la violència moral i física que és la novel la. Aquesta consideració, però, va unida indefectiblement a un procés d'alterització dels personatges que són intervinguts en la taula d'operacions. Es tracta d'una prostituta, un home de taverna i un violador de carrer. En els tres casos, són arquetips que, a banda de representar els baixos fons de la societat, són l'antagonista més directe als principis il lustrats que malden per exercir la crítica davant dels actes guiats per les passions i les creences.

Paradoxalment, Brunel la, empesa pel desig de perfecció i inicialment guiada per la màxima del mestre, «Si perseveres, seràs purificat, sortiràs de l'abisme de les tenebres i veuràs la llum» (Moner 2011: 31), inicia, com déiem, un cicle d'experiments que també l'allunyarà de la racionalitat defensada pel seu mestre. Aquest llega el seu coneixement a l'aprenent en els següents termes:

Ens ha de moure la capacitat d'esforç i de superació, aprofitar els dons que ens atorga la Naturalesa per a dedicar-los al bé públic. (...) Em dominava el pensament d'observar diligentment els fenòmens que apareixen davant dels nostres sentits tant en l'home sa com en el malalt, en el moribund i, per què no, en el cadàver. (...) Però per poder finalitzar amb èxit aquesta empresa havia d'arribar a un tal grau de sapiència que em permetés esgarrar el vel mut 
i invisible que cobreix l'ésser de les coses i acorralar així la bèstia interna que ens consagra a la mort. aqueixa bèstia inextingible que ens mata en tant que vivim (Moner 2011: 56).

En canvi, la confiança en els avanços científics com a motor de millora social és interpretada en la deixebla com l'únic camí per a defugir del cos grotesc en què estava atrapada. En la primera de les intervencions relatades per Moner ja s'observen les inclinacions que mouen la protagonista. Damunt la taula d'operacions jeu una prostituta raptada per Zacaries per a assajar la cirurgia en un ésser viu, la qual cosa incomoda el jove:

El sorprenia la naturalitat amb la qual es comportava Brunel la, la serenor amb què donava les ordres, possiblement el secret consistia a saber distanciar-se'n, a no pensar en l'atrocitat de l'acte, a només executar-lo, talment com si es tractàs d'un cadàver, de segur que ella ho veia així (Moner 2011: 64).

El distanciament acusat en la narració entre Brunel la i la dona raptada, ara reduïda a un cos on experimentar i observar el flux de la sang, respon a una alterització dels personatges marginals convertits en objectes científics. Aquesta consideració de l'altre com un ésser llunyà i deshumanitzat es posa de manifest en el moment del traspàs de la primera víctima, que provoca en la protagonista el següent argumentari:

Brunel la estengué les mans, que brutes de sang resseca adquirien un aspecte veritablement monstruós, i les mantingué enlairades damunt del cos exànime mentre les mirava amb fàstic. La idea d'arrossegar aquesta deformitat de per vida la paralitzava.

-No ens aturarem! Em sents? (...) No es tracta d'una quimera, d'un somni de noieta ploramiques! Em coneixes, xicon! Saps que ho assolirem! No importa si n'has de raptar tres, deu o vint, de desgraciats! (Moner 2011: 76).

El traspàs de la primera víctima i la reacció que desencadena reforça la presència de l’abjecció en la narració, la qual ja no afecta només el cos grotesc de la protagonista sinó que s'amplia als fets perpetrats arran d'aquesta realitat. La mort dels cossos en les viviseccions expressa el límit de la condició de la vida, fa fracassar la idea de progrés assignada a la ciència i impregna d'abjecció el món dels vius, sobretot, amb la presència del cadàver.

En aquest sentit, la taula d'operacions i l'anomenada «cambra dels morts» són els llocs clau en què s'amplifica l'escletxa entre la vida i la mort, són les zones que acullen la infecció i les despulles abans de l'exhalació definitiva. Encara que no es tracte de la referència explícita als cadàvers, en la narració abunden les descripcions agòniques dels cossos en trànsit, un mecanisme que activa una percepció sinestèsica del text literari, entre l'olfacte i la visió, i que podríem considerar més l'avantsala de l'abjecció pura, com es veu en aquest fragment referit l'operació d'una altra víctima: «Aprecià el braç més inflamat, així que retirà el tros de tela que li cobria el canell: la ferida estava ulcerada, tumefacta i amerada d'una mucositat verdosenca, freda, vescosa i molt pútida» (Moner 
2011: 156). Posteriorment, la pèrdua envaeix l'estança quan Zacaries entra a comprovar l'estat de l'home amputat:

\begin{abstract}
El braser encara crepitava enmig de l'obagor, però la ferum picant de la podridura del drenatge s'imposava a l'aroma fresca i salutífera d'abans. El cos abandonat del Perla ja no tremolava a causa de les convulsions i de la febre. L'aliança existent entre els cossos i el fil invisible que els manté en vida havia estat trencada (Moner 2011: 159).
\end{abstract}

Amb la presència del cadàver s'han ampliat els límits de la mort, l'ambient ha canviat d'aroma i ha generat uns canvis morals clarament perceptibles en l'etopeia de l'ajudant, que és el testimoni directe de l'expressió màxima de l'abjecció, la mort infestant la vida (Kristeva 2006: 11). Com déiem, l'impacte del traspàs té efectes directes sobre l'ordenació moral de Zacaries, el qual, paradoxalment, es reafirma com un personatge identificat amb les víctimes de la mestra:

\footnotetext{
Malgrat la familiaritat amb el sofriment, la misèria i, evidentment, amb els difunts, la mort d'aquell desgraciat l'afectà, s'adonava que tots els cadàvers que havien passat per aquella estança, també el de la meuca i, ara, el del Perla, narraven sense paraules una bona part de la seua història. (...) Persones anònimes que, igual que ell, havien aprés des de la infantesa que l'horitzó de la vida es podia abreujar en un instant (Moner 2011: 160).
}

Els paràmetres d'aquest personatge posen de manifest que, a diferència de Brunel la, és un subjecte conscient de la seua condició i amb una identitat estable, encara que manifestament subalterna i supeditada a la seua ama. Altrament, la protagonista és dibuixada per Moner com un ésser amb una identitat fràgil, pertorbada per la deformació de les mans, la qual cosa la situa en un pla abjecte marcat per la transgressió de la racionalitat i l'obsessió en l'experimentació. Kristeva afirma que és abjecte allò que posa en dubte la llei: «Todo crimen, porque señala la fragilidad de la ley, es abyecto, pero el crimen premeditado, la muerte solapada, la venganza hipócrita lo son aun más porque aumentan esta exhibición de fragilidad legal» (Kristeva 2006: 12). En conseqüència, les accions de Brunel la van un pas més enllà i marquen la debilitat de la llei de la vida i de la llei de la ciència de què Scarpa era guardià en negar-se a amputar i reimplantar la seua deixebla.

L'exemple més clar en què s'evidencia l'abjecció del relat és arran del tercer, i últim, experiment de la protagonista: la dissecció d'un subjecte sense anestèsia. A diferència de les intervencions anteriors, en aquest cas la cirurgiana decideix operar l'últim segrestat immediatament després de la mort del Perla sense alleugerir-li el dolor en descobrir-ne la identitat. Quan la protagonista reconeix la víctima que li ha subministrat Zacaries es desvelen les intencions de la intervenció i Brunel la li explica els motius pels quals no hi haurà anestèsia: «Encara no saps qui sóc, veritat? Tal vegada si anàs vestida amb la capeta púrpura i el gipó roig hi reconeixeries la donzella manca que vas forçar l'altra matinada (...)» 
I continua després d'haver-li mostrat el dit bífid:

- El cos d'una dona mai no s'ha de ferir i molt menys el d'una dona com jo. Havia decidit oblidar-te per tal de fer més suportable la humiliació a la qual em vas sotmetre, però, amic meu, la teua malastrugança m’alleugerà la ràbia i, en certa manera, t’ajudarà a redimir la culpa. Et vas equivocar en abusar de mi, mai no has de subestimar a qui desconeixes. En uns instants comprendràs el que vull dir; els meus coneixements, el meu cos i les meues mans esdevindran per a tu una arma feridora capaç d'infligir-te un suplici refinat i diligent (Moner 2011: 176-177).

En aquest punt la protagonista s'autoafirma com a víctima de violència sexual radicada en l'existència material de la carn: una vegada més, es tracta del cos situat i ultratjat. Ara, però, la consciència corporal va un pas més enllà i ja no és només l'instrument i l'objecte per al coneixement científic en el procés de restauració de les extremitats. Sinó que estem davant de l'assumpció de la corporeïtat com a part constitutiva del trauma viscut per la protagonista, ella és el cos capaç de venjar el dolor patit, com es veu en el fragment suara citat. La mort del darrer subjecte posa de manifest la perversió en el moment que, com diu Kristeva «mata en nombre de la vida (...) realimenta el sufrimiento del otro para su propio bien» (2006: 25), com ocorre en aquest cas.

Des del punt de vista narratiu, la tònica del desenllaç de la novel la continua en l'espiral representació material del dolor i el cos intervingut a la llum de la ira de Brunel la no sobreviu. Aquest darrer fracàs mèdic provoca en la protagonista una angoixa vital incontrolable que l'aboca consum de làudan inusual, tot sumint-la en un estat transitori entre somni i vigília. Aquesta situació empeny Zacaries a tocar la seua mestra impulsat pel desig sexual que aquesta havia alimentat en l'ajudant temps enrere. L'intent de posseir-la, però, la desperta del somni narcòtic i reacciona contra el contacte tot rebutjant iradament Zacaries de cos i de paraula. El jove intenta retindre-la i fer-se entendre entre disculpes i explicacions, però, no obstant això, Brunel la el fereix amb les ungles del dit bífid. L'acte violent amb la garra deforme la situa en un primer pla de l'acció i la converteix en actant directe per a propiciar una baralla que acaba amb el braç de la mestra seccionat accidentalment. Davant de la inconsciència per l'impacte, l'ajudant obra com la mestra sempre havia anhelat, l'opera; en canvi, Brunel la en despertar immersa en el pànic i conscient l'esdevenir dels fets percep el seu cos ferit i infectat $\mathrm{i}$ es reconeix:

enxampada en el seu propi parany. Per uns segons es veié a l'altre costat de l'espill, atrapada dins de la superfície mercurial de l'imperfecte mirall. (...) Un llampec la recorregué de cap a peus, era una víctima més, tot i que, en aquest cas víctima de Zacaries (Moner 2011: 215).

Posteriorment, l'obra finalitzarà amb la mort de la protagonista a causa de les febres produïdes per la intervenció. 


\section{A tall de conclusions}

En síntesi, Les mans de la deixebla se'ns presenta com una novel la complexa des del punt de vista de la construcció psicològica dels personatges, els quals resulten polièdrics i canviants en funció de les relacions que s'estableixen entre ells. En aquest sentit, l'obra de l'autora valenciana és una producció literària original capaç d'encastar el discurs filosòfic de la Il lustració a través de la figura del cirurgià Scarpa, atrapat entre el desig i la contingència, amb la contradictòria força de l'obsessió per la perfecció encarnada en Brunel la i les passions incontrolables de Zacaries. Moner crea, d'aquesta manera, una tríada de personatges incardinada en un punt comú: la consciència d'una corporeïtat conflictiva. Més enllà del tòpic raó-passions la novel la explicita la degradació de l'ideari de progrés que la ciència del segle XVIII defensava com a mitjà de millora social. Aquest pensament es veu corromput per la força de l'obsessió que empeny Brunel la a modificar el seu cos. La ciència de la cirurgia abandona la funció social que Scarpa havia defensat com a canal per al bé comú i es converteix en un agent que alimenta la condició abjecta de la protagonista.

En aquest sentit, la ciència il lustrada queda afectada pels efectes de la perversió fins al punt que serveix a Brunel la com a mètode de venjança contra aquell que l'agredí sexualment. El coneixement no fa avançar la tècnica mèdica sinó que la insistència en assolir l'èxit personal la condemna a la manca de claredat necessària en l'activitat intel lectual. Certament, la protagonista de la novel la encarna a la perfecció aquesta transformació dels usos de la ciència a causa de l'anhel per trobar la perfecció. El conflicte amb la corporeïtat, per tant, parteix d'un clar distanciament que alteritza les mans de Brunel la com ja havia avançat Abelló en els metres «Les mans són una cosa, /jo en sóc una altra. /Elles tenen la seva vida», i desemboca en un procés d’abjecció en què són utilitzades per a infligir dolor en un cos aliè. 


\section{Bibliografia}

Abelló, M. (2002) Al cor de les paraules. Obra poètica 1963-2002, Barcelona, Proa.

Aliaga, X. (2015) «La mòrbida elegància d'Anna Moner» Núvol, el digital de cultura [última consulta 31/10/2019: https://www.nuvol.com/critica/la-morbida-elegancia-danna-moner/]

—. (2019) «Anna Moner i l'excursió cap a les profunditats de l'ànima», Blog Xavier Aliaga. Sota la creueta [última consulta 31/10/2019: https://xavieraliaga.cat/2019/07/anna-moner-ilexcursio-cap-a-les-profunditats-de-lanima.html]

Conrich, I. i Sedgwick, L. (2017) «Hands» dins Conrich, I. i Sedgwick, L. Gothic Dissections in Film and Literature. The boy in parts, Londres, Palgrave Macmillan, pp.131-150.

Kristeva, J. (2006) Poderes de la perversió. Ensayo sobre Lonis-Ferdinand Celine, Mèxic, Siglo Veintiuno Editores.

López, M. (2008) «Teoría de la novela gótica», Estudios humanísticos. Filología, 30, pp. 187-210.

Marcer, E. (2012) «El cos és l’altre: simultaneïtat i tacte en la poesia de Montserrat Abelló», Catalan Review, 26, pp.183-199.

Moner, A. (2011) Les mans de la deixebla, Alzira, Bromera.

—. (2015) El retorn de l'hongarès, Alzira, Bromera.

—. (2019) La mirada de vidre, Alzira, Bromera.

Villalonga, A. (2015) «Anna Moner. El retorn de l’Hongarès», Núvol, el digital de cultura [última consulta: 31/10/2019: https://www.nuvol.com/critica/anna-moner-el-retorn-de-lhongares-2/] 